\title{
A Survey on Growth and Nutritional Status of Children with Cerebral Palsy in the Northwest Iran
}

\author{
Vahideh Toopchizadeh, ${ }^{1}$ Mohammad Barzegar, ${ }^{2}$ Navid Madinei, ${ }^{1}$ and Fatemeh Jahanjoo ${ }^{1, *}$ \\ ${ }^{1}$ Physical Medicine and Rehabilitation Research Center, Tabriz University of Medical Sciences, Tabriz, Iran \\ ${ }^{2}$ Pediatric Health Research Center, Tabriz University of Medical Sciences, Tabriz, Iran \\ "Corresponding author: Fatemeh Jahanjoo, Physical Medicine and Rehabilitation Research Center, Tabriz University of Medical Sciences, Golgasht Ave, Tabriz, Iran. Tel/Fax: \\ +98-4133373967, E-mail: f.jahanjou@yahoo.com
}

Received 2016 November 02; Revised 2017 March 05; Accepted 2017 April 18.

\begin{abstract}
Background: Cerebral palsy (CP) is the leading cause of childhood disability. Children with CP are at risk for growth and nutritional disorders. The current study aimed at evaluating the growth and nutritional status of children with CP and assessing the relationship between the studied variables, clinical presentation, disease severity, and functional level in these patients in Northwest Iran. Methods: In the current cross sectional, descriptive study, 99 outpatient children with CP referring to the rehabilitation clinic of children's Medical center in Tabriz, Iran, were studied for a 12-month period from June 2015 to June 2016. Demographic variables, CP type, anthropometric measures, and GMFCS (gross motor function classification system) were recorded. The patients' weight and height were measured, and then, weight-for-age and height-for-age percentiles were calculated based on the percentile charts for all patients. Dietary intake of the children was determined by the 24-hour dietary recalls of 3 nonconsecutive days ( 2 weekdays and 1 weekend day) by asking their parents as reliable reporters.

Results: Sixty-four patients had inadequate calorie intake, while 47 and 42 patients had abnormal weight and height percentiles. Quadriplegic and diplegic types $\mathrm{CP}$, compared with the hemiplegic type $(\mathrm{P}=0.003$ and $\mathrm{P}=0.043)$, and GMFCS III to V, compared with the classes I and II $(\mathrm{P}=0.001)$, had significantly less normal weight percentiles, but there were no significant differences between normal and abnormal height percentiles, based on CP type and GMFCS level.

Conclusions: Abnormal growth was significantly common in children with quadriplegic and diplegic CP and high GMFCS level. About $64 \%$ of the children had inadequate calorie intake. Nutritional management should be arranged for the undernourished children to promote their nutritional status and improve their growth and functional capacities.
\end{abstract}

Keywords: Growth Failure, Children, Cerebral Palsy, Calorie Intake

\section{Background}

Cerebral palsy (CP), a common cause of disability in children, persists throughout life and is characterized by persistent disorders in posture and motor control that result from non-progressive brain lesions (1). Furthermore, children with $\mathrm{CP}$ experience several problems related to sensation, cognition, communication, and behavioral disturbances, epilepsy, and secondary musculoskeletal complications (2). Children with CP experience limitations in their daily activities (e.g., feeding, dressing, bathing, and mobility) due to abnormal motor control, gait problems, imbalance, and poor social functioning $(3,4)$. They also experience difficulty in swallowing. Feeding difficulties and malnutrition are the 2 problems associated with $\mathrm{CP}(5)$.

Growth and nutritional disorders are common in children with CP. As previously described (6-8), due to oral motor dysfunction, gastroesophageal reflux, and food refusal, the total caloric intake of children with CP is inadequate, which results in undernourishment and growth im- pairment. Neurological impairment along with malnutrition and low caloric intake may lead to slow linear growth and weight gain, which accompanies the lower height and weight in children with $\mathrm{CP}$, compared with their healthy counterparts $(9,10)$.

Although nutritional and growth disorders may occur in all children with $\mathrm{CP}$, according to the reports, it is more common among the patients with greater degrees of motor impairments (10-12). Abnormal growth manifestations, such as malnutrition and obesity, are controversial while taking care of children with CP. To design a better program to improve the health status of children with $\mathrm{CP}$, it is important to assess the growth and nutritional status of such patients in each geographical region. The current study aimed at evaluating the growth and nutritional status of children with CP in Northwest Iran. 


\section{Methods}

The current cross sectional study recruited 99 outpatient children with CP referring to the Rehabilitation clinic of the children's Medical center in Tabriz, Iran. The Tabriz Children's Medical center is the largest medical center for pediatrics in Northwest Iran. The children were randomly selected over a 12-month period from June 2015 to June 2016. Patients within the age range of 3 to 12 years and confirmed diagnosis of CP were included, regardless of gender. Exclusion criteria were the history of genetic, metabolic, or neurodegenerative disease, and other medical conditions that affect growth. The study was approved by the research ethics committee of Tabriz University of Medical Sciences. Written informed consent was obtained from the parents or legal guardians of the children.

Demographic variables, $\mathrm{CP}$ type, anthropometric measures, and gross motor function classification system (GMFCS) were evaluated. Patients were classified as spastic, dyskinetic or extrapyramidal, cerebellar or ataxic, hypotonic or mixed type, based on the motor impairment (1).

\subsection{Weight Measurement}

A zero-calibrated digital scale, in kilograms, was used to measure the weight of the children without cloths. Alternatively, weight was calculated as the difference between the caregiver's weight with and without the child.

\subsection{Height Measurement}

A stadiometer was used to measure the height of children in centimeters in an upright or standing position and was performed on those individuals who had no major skeletal deformities (e.g., scoliosis, kyphosis, or structural deformities in lower limb flexion).

The knee height equation was used to estimate the height for those with deformities, where: height $=(2.69$ $\times$ knee height $)+24.2(13)$. The formula utilizes the height from the knee to the heel to estimate the overall height. It is the most frequently used height estimation system as it exhibits the smallest error rate relative to the exact height (14). The measured values were evaluated in the growth charts and their weight-for-age and height-for-age percentiles were calculated.

The children below the 5 th percentile were categorized as malnourished cases, those between the 5th and 95th percentiles as normal weight, and those $>95$ th percentile as overweight $(15,16)$.

\subsection{Calorie Intake}

Dietary intake of children was determined based on the 24-hour dietary recalls of 3 nonconsecutive days (2 weekdays and 1 weekend day) by asking their parents as the most reliable reporters (17). The data were analyzed by the mean values collected from 3 questionnaires.

In all cases, the feeding route was oral. The type and amount of foodstuff consumed within a 24-hour (midnight to midnight) by the children for the day preceding the interview were recorded using the automated multiple-pass method. N4 (Nutritionist IV) software was used to compare the daily calorie intake with the recommended rates, based on height and weight (18).

\subsection{GMFCS}

GMFCS is a standard observational tool used to assess children with CP; it evaluates the ability to perform movements such as walking, climbing stairs, running, and sitting. According to this scale, children were stratified into 5 grades from I to $\mathrm{V}$ according to their gross motor skills, with lower levels representing better gross motor skills (i.e., I refers to the lightest level of impairment and V is the most severe level of impairment) (18).

\subsection{Sample Size Determination}

According to the results of similar studies, the current study was powered to detect an effect size of $d=0.1$ as statistically significant in a 2-tailed test with $\alpha=0.05$ and an expected proportion of 0.50 with $\mathrm{N}=90$. By the estimation of $10 \%$ dropouts in the study subjects from the last followup appointment, 99 children were included in the study.

\subsection{Statistical Analysis}

Data were analyzed with SPSS software (version 21.0, SPSS Inc., Chicago, IL, USA). Quantitative data were expressed as mean \pm standard deviation (SD), while qualitative data were reported as the frequency and percentage. Categorical variables were analyzed using the chi-square test, or the Fisher exact test, if needed. Simple logistic regression was used to explore the association between dichotomous outcomes and predictor variables. $\mathrm{P}<0.05$ was considered as the level of significance.

\section{Results}

The current descriptive study evaluated 99 outpatient children with CP, aged 2 to 13 years, from March 2014 to May 2015. Table 1 demonstrates the baseline findings in the study population. Most cases were male, with spastic and quadriplegic types of CP and GMFCS levels of II or III. More than half of the patients had normal weight and height, but two-thirds of them had an inadequate level of daily calorie intake. 
Table 1. Baseline Findings of the Study Population

\begin{tabular}{|c|c|c|c|}
\hline Variable & Category & Frequency & Percent \\
\hline Age, $y$, mean $\pm S D$ & $7.49 \pm 2.51$ & & \\
\hline \multirow{2}{*}{ Gender } & Female & 44 & 44.4 \\
\hline & Male & 55 & 55.6 \\
\hline \multirow{3}{*}{ Physiotherapy history } & Regular & 43 & 43.4 \\
\hline & None & 1 & 1.0 \\
\hline & Irregular & 55 & 55.6 \\
\hline \multirow{2}{*}{ Walking ability } & Yes & 46 & 46.5 \\
\hline & No & 53 & 53.5 \\
\hline \multirow{2}{*}{ Anticonvulsant drugs usage } & Yes & 25 & 25.3 \\
\hline & No & 74 & 74.7 \\
\hline \multirow{2}{*}{ Orthopedic surgery } & Yes & 6 & 6.1 \\
\hline & No & 93 & 93.9 \\
\hline \multirow{3}{*}{ Palsy type } & Quadriplegic & 44 & 44.4 \\
\hline & Diplegic & 37 & 37.4 \\
\hline & Hemiplegic & 18 & 18.2 \\
\hline \multirow{4}{*}{ CP type } & Mixed & 7 & 7.1 \\
\hline & Dyskinetic & 4 & 4.0 \\
\hline & Spastic & 72 & 72.7 \\
\hline & Hypotonic & 16 & 16.2 \\
\hline \multicolumn{4}{|l|}{ GMFC level } \\
\hline \multirow{2}{*}{ I-II } & I & 7 & 7.1 \\
\hline & II & 42 & 42.4 \\
\hline \multirow{3}{*}{ III- $\mathrm{V}$} & III & 36 & 36.4 \\
\hline & IV & 9 & 9.1 \\
\hline & $\mathrm{v}$ & 5 & 5.1 \\
\hline Serum calcium level, mean $\pm \mathrm{SD}$ & $9.82 \pm .59$ & & \\
\hline $\begin{array}{l}\text { Serum 25-OH vitamin D3 level, mean } \\
\pm \text { SD }\end{array}$ & $29.23 \pm 24.20$ & & \\
\hline \multirow[t]{4}{*}{ Weight } & $16.30 \pm 7.35$ & & \\
\hline & Normal (5th - 95th percentile) & 52 & 52.5 \\
\hline & Abnormal ( $<$ th percentile) & 45 & 45.5 \\
\hline & Abnormal (> 95th percentile) & 2 & 2.0 \\
\hline \multirow[t]{4}{*}{ Height } & $105.27 \pm 17.90$ & & \\
\hline & Normal (5th - 95th percentile) & 57 & 57.6 \\
\hline & Abnormal ( $<5$ th percentile) & 34 & 34.3 \\
\hline & Abnormal ( $>$ 95th percentile) & 8 & 8.1 \\
\hline \multirow{3}{*}{ Calorie intake } & $1374.65 \pm 465.69$ & & \\
\hline & Sufficient & 35 & 35.4 \\
\hline & Insufficient & 64 & 64.6 \\
\hline \multirow{3}{*}{ Calcium intake } & $703.09 \pm 359.85$ & & \\
\hline & Sufficient & 43 & 43.4 \\
\hline & Insufficient & 56 & 56.6 \\
\hline \multirow{3}{*}{ Protein intake } & $835.94 \pm 454.84$ & & \\
\hline & Sufficient & 99 & 100.0 \\
\hline & Insufficient & 0 & 0.0 \\
\hline
\end{tabular}

There were few patients in the $>$ 95th percentile for weight and height. In order to evaluate differences between the growth markers and related factors, patients were divided into 2 groups of normal and abnormal weight and height. To evaluate the nutritional status of children with $\mathrm{CP}$ more accurately, patients were categorized based on GMFCS levels into either I-II or GMFCS III-V (Table 2). The prevalence of abnormal weight was statistically higher in children with severe forms of $\mathrm{CP}$ such as quadriplegic and diplegic, compared with the children with hemiplegic $\mathrm{CP}$. Children with quadriplegic and diplegic CP were 7.94- and 4.25-times more likely to predispose abnormal weight than the ones with hemiplegic $\mathrm{CP}$, respectively $(\mathrm{P}=0.003$ and $\mathrm{P}=0.043)$.

Although there was no significant association between the CP type and weight percentile, the children with mixed $\mathrm{CP}$ were 10-times more likely to develop abnormal weight, compared with the ones with hypotonic CP $(85.7 \%$ vs. $37.5 \%)$. The results also indicated that, by increasing GMFCS level, the rate of abnormal weight percentile significantly increased $30.6 \%$ vs. $64.0 \%$ for level I-II, compared with level IV-V, respectively; OR: 0.25, 95\%CI: $0.11-0.57$, P $=0.001)$. Increase of serum calcium levels was associated with a decreased likelihood of abnormal weight (OR 0.37, 95\%CI: 0.14 - 0.94, P = 0.036).

Children with walking abnormalities were significantly 5.49-times more likely to predispose abnormal height. The results also demonstrated that children with mixed CP were more likely to predispose abnormal height, compared with the ones with hypotonic $\mathrm{CP}$, although the relationship was not statistically significant (OR: 7.71, 95\%CI: 0.75 - 79.77, P= 0.087).

The last section of Table 2 compares the nutritional status (calorie intake) among the categories of related factors. Although inadequate calorie intake was higher in quadriplegic and spastic types of $\mathrm{CP}$ and increased based on the GMFCS level, there was no significant differences in the nutritional status.

A comparison of serum 25-OH vitamin D levels and physiotherapy history with the categories of weight percentile, height percentile, and nutritional status did not show any significant differences.

\section{Discussion}

The current study evaluated the growth and nutritional status among 99 children with $\mathrm{CP}$ within the age range of 3 to 12 years, living in the Northwest Iran, and found inadequate calorie intake in $64.6 \%$ below the 5 th percentile and over the 95th percentile of weight-for-age and height-for-age in $45.4 \%, 2 \%, 34.3 \%$, and $8.1 \%$, respectively. In the current study, most patients had low body-weight.

The results were inconsistent with those of the studies showed that lower weight was more frequent among children with CP, although obesity and overweight showed increase in such children (19-22). These differences could be due to poor or inadequate nutrition. The current study 
Table 2. Factors Related to Weight Percentiles, Height Percentiles, and Nutritional Status in the Subjects with CP

\begin{tabular}{|c|c|c|c|}
\hline Variable & Abnormal, No. (\%) & Pvalue & Odds Ratio (95\% CI) \\
\hline \multicolumn{4}{|c|}{ Weight } \\
\hline Walking ability & & $0.051^{\mathrm{a}}$ & \\
\hline Yes & $17(37.0)$ & & $0.45(0.20-1.00)$ \\
\hline No & $30(56.6)$ & & Reference group \\
\hline Palsy type & & $0.006^{\mathrm{a}}$ & \\
\hline Quadriplegic & $27(61.4)$ & & $7.94(1.99-31.57)$ \\
\hline Diplegic & $17(45.9)$ & & $4.25(1.05-17.20)$ \\
\hline Hemiplegic & $3(16.7)$ & & Reference group \\
\hline CP type & & $0.091^{\mathrm{b}}$ & \\
\hline Mixed & $6(85.7)$ & & $10.00(0.95-104.49)$ \\
\hline Dyskinetic & $3(75.0)$ & & $5.00(0.42-59.66)$ \\
\hline Spastic & $32(44.4)$ & & $1.33(0.44-4.06)$ \\
\hline Hypotonic & $6(37.5)$ & & Reference group \\
\hline GMFC level & & $0.001^{\mathrm{a}}$ & \\
\hline I and II & $15(30.6)$ & & $0.25(0.11-0.57)$ \\
\hline III-V & $32(64.0)$ & & Reference group \\
\hline \multicolumn{4}{|c|}{ Height } \\
\hline Walking ability & & $<0.001^{\mathrm{a}}$ & \\
\hline Yes & $10(21.7)$ & & Reference group \\
\hline No & $32(60.4)$ & & $5.49(2.25-13.37)$ \\
\hline Palsy type & & $0.260^{\mathrm{a}}$ & \\
\hline Quadriplegic & $22(50.0)$ & & $2.60(0.79-8.53)$ \\
\hline Diplegic & $15(40.5)$ & & $1.77(0.52-6.02)$ \\
\hline Hemiplegic & $5(27.8)$ & & Reference group \\
\hline CP type & & $0.106^{\mathrm{b}}$ & \\
\hline Mixed & $6(85.7)$ & & $7.71(0.75-79.77)$ \\
\hline Dyskinetic & $2(50.0)$ & & $1.29(0.14-11.54)$ \\
\hline Spastic & $27(37.5)$ & & $0.77(0.26-2.31)$ \\
\hline Hypotonic & $7(43.8)$ & & Reference group \\
\hline GMFC level & & $0.123^{\mathrm{a}}$ & \\
\hline I and II & $17(34.7)$ & & $0.53(0.24-1.19)$ \\
\hline III-V & $25(50.0)$ & & Reference group \\
\hline \multicolumn{4}{|c|}{ Nutritional Status (Calorie Intake) } \\
\hline Walking ability & & $0.340^{\mathrm{a}}$ & \\
\hline Yes & $32(69.6)$ & & $1.50(0.65-3.46)$ \\
\hline No & $32(60.4)$ & & Reference group \\
\hline Palsy type & & $0.803^{\mathrm{a}}$ & \\
\hline Quadriplegic & $30(68.2)$ & & $1.36(0.44-4.26)$ \\
\hline Diplegic & $23(62.2)$ & & $1.04(0.33-3.32)$ \\
\hline Hemiplegic & $11(61.1)$ & & Reference group \\
\hline CP type & & $0.120^{\mathrm{b}}$ & \\
\hline Mixed & $4(57.1)$ & & $1.33(0.22-7.98)$ \\
\hline Dyskinetic & $1(25.0)$ & & $0.33(0.03-3.93)$ \\
\hline Spastic & $51(70.8)$ & & $2.43(0.80-7.32)$ \\
\hline Hypotonic & $8(50.0)$ & & Reference group \\
\hline GMFC level & & $0.122^{\mathrm{a}}$ & \\
\hline I and II & $28(57.1)$ & & $0.52(0.22-1.20)$ \\
\hline III-V & $36(72.0)$ & & Reference group \\
\hline \multicolumn{4}{|c|}{$\begin{array}{l}\text { Abbreviations: CP, Cerebral Palsy; GMFCS, Gross Motor Function Classification System. } \\
\text { a Pearson chi-square test. }\end{array}$} \\
\hline
\end{tabular}

also observed that most children with $\mathrm{CP}$ had inadequate calorie intake. Similarly, it was reported that the calorie intake of children with CP was lower than that of the agematched controls $(23,24)$.

When a child cannot take essential nutrients due to difficulty in feeding, the scarcity of foodstuff, or when the needs of the child exceeds food intake due to an increase in the metabolic rate, the malnutrition occurs. It was suggested that feeding difficulties can interfere with the calorie intake required for the energy needs of children; thereby, it probably results in a decrease of the linear growth and a serious risk of malnutrition $(9,19)$. Multiple etiologies such as motor disability, inadequate nutritional intake, and motor dysfunction were suggested as the factors causing malnutrition in children with CP (6-8). Inadequate nutrition may increase healthcare costs and limit functional mobility, particularly in children with severe motor impairments $(21,25,26)$. Nutrition is an important factor to manage children with CP; therefore, appropriate and early nutritional support and follow-up are necessary to ensure adequate growth, improved quality of life, and optimized functional status.

Previous results indicated that children with CP were at risk of malnutrition. Studies also reported that the severity of malnutrition and growth problems differed regarding the CP type (27). Stallings et al., (28) reported that children with hemiplegia or diplegia experienced a reduced linear growth and 30\% of such children were also undernourished. In another study on children with spastic quadriplegia, the researchers also noted a reduction in linear growth and body weight $(29,30)$. In addition, the calorie requirements were different for the various types of CP. For example, children with hypotonic and non-ambulatory CP did not require calories more than that to sustain the resting energy expenditure (31); while children with athetoid CP had an increased demand for calories $(32,33)$. Similarly, children with diplegic or hemiplegic CP required more calories to sustain their daily activities than the normal children $(33,34)$.

The current study showed that the rate of inadequate calorie intake was higher in patients with quadriplegic and spastic CP, but the difference was not significant. The need for energy showed increase in the patients with spastic $\mathrm{CP}$, compared with the ones with hypotonic type; since they had a significantly higher rate of inadequate calorie intake. Patients with the quadriplegic $\mathrm{CP}$, compared with diplegic and hemiplegic types, had significantly lower normal weight percentiles, but no significant difference was observed between spastic and hypotonic CP types regarding weight or height percentiles.

According to the results of the current study, with increase in the plegic limbs, the lower weight and height in- 
creases; In an another study, (34) also reported low values of height-to-age percentile in the individuals with tetraplegia. Other reports were also inconsistent with these findings $(19,35,36)$.

Studies also showed that decreased nutritional status in children with CP was related to decreased mobility (GMFCS)(26). Brooks et al., (16) reported that children in GMFCS levels I and II had significantly better weight than the ones in GMFCS levels III, IV, and V. Similarly, with the increased GMFCS levels, the rate of normal weight percentile significantly reduced. Although not significant, patients with GMFCS levels III, IV, and V more frequently take inadequate calories than the children with GMFCS levels I and II.

The study had some limitations; first, the large sample of patients for GMFCS II and II, which may affect the interpretation of the results regarding the GMFCS levels. The sample size was rather small; as the patients were just recruited from a tertiary care hospital. Evaluation of children with $\mathrm{CP}$ from different centers could increase the sample size and allow the generalization of results. It is also possible that family income affected the nutritional status of children; however, the study did not evaluate this variable in the population.

In conclusion, inadequate calorie intake and growth problems are common in children with $\mathrm{CP}$ and nutritional management should be arranged for undernourished children to improve their nutritional status, growth, and functional capacity.

\section{Acknowledgments}

The authors are grateful to all participants who helped to conduct the study, especially the children and their parents. The authors would like to thank the staff of Tabriz Children's Medical Center, Tabriz, Iran for their assistance.

\section{Footnotes}

Authors' Contribution: Vahideh Toopchizadeh, study design, writing the manuscript, and contributing the research conduction and reporting; Mohammad Barzegar, protocol development; Navid Madinei, drafting the protocol and data collection; Fatemeh Jahanjoo, abstracting, analyzing, and interpreting the data, and contributing in writing and preparing the manuscript.

Funding/Support: The study was financially supported by Tabriz University of Medical Sciences.

\section{References}

1. Bax M, Goldstein M, Rosenbaum P, Leviton A, Paneth N, Dan $\mathrm{B}$, et al. Proposed definition and classification of cerebral palsy, April 2005. Dev Med Child Neurol. 2005;47(8):571-6. doi: 10.1017/S001216220500112X. [PubMed: 16108461].

2. Rosenbaum P, Paneth N, Leviton A, Goldstein M, Bax M, Damiano D, et al. A report: the definition and classification of cerebral palsy April 2006. Dev Med Child Neurol Suppl. 2007;109:8-14. [PubMed: 17370477].

3. Berker N, Yalçın S. . The help guide to cerebral palsy. ; 2010.

4. Brehaut JC, Kohen DE, Raina P, Walter SD, Russell DJ, Swinton M, et al. The health of primary caregivers of children with cerebral palsy: how does it compare with that of other Canadian caregivers? Pediatrics. 2004;114(2):e182-91. doi: 10.1542/peds.114.2.e182. [PubMed: 15286255].

5. Odding E, Roebroeck ME, Stam HJ. The epidemiology of cerebral palsy: incidence, impairments and risk factors. Disabil Rehabil. 2006;28(4):183-91. doi: 10.1080/09638280500158422. [PubMed: 16467053].

6. Andrew MJ, Parr JR, Sullivan PB. Feeding difficulties in children with cerebral palsy. Arch Dis Child Educ Pract Ed. 2012;97(6):222-9. doi: 10.1136/archdischild-2011-300914. [PubMed: 22293504]

7. Kilpinen-Loisa P, Pihko H, Vesander U, Paganus A, Ritanen U, Makitie O. Insufficient energy and nutrient intake in children with motor disability. Acta Paediatr. 2009;98(8):1329-33. doi: 10.1111/j.16512227.2009.01340.x. [PubMed: 19432830].

8. Araujo LA, Silva LR, Mendes FA. Digestive tract neural control and gastrointestinal disorders in cerebral palsy. J Pediatr (Rio J). 2012;88(6):455-64. doi: 10.2223/JPED.2241. [PubMed: 23269445].

9. Fung EB, Samson-Fang L, Stallings VA, Conaway M, Liptak G, Henderson RC, et al. Feeding dysfunction is associated with poor growth and health status in children with cerebral palsy. J Am Diet Assoc. 2002;102(3):361-73. doi: 10.1016/S0002-8223(02)90084-2. [PubMed: 11902369].

10. Day SM, Strauss DI, Vachon PJ, Rosenbloom L, Shavelle RM, Wu YW. Growth patterns in a population of children and adolescents with cerebral palsy. Dev Med Child Neurol. 2007;49(3):167-71. doi: 10.1111/j.1469-8749.2007.00167.x. [PubMed: 17355471].

11. Clancy KJ, Hustad KC. Longitudinal changes in feeding among children with cerebral palsy between the ages of 4 and 7 years. Dev Neurorehabil. 2011;14(4):191-8. doi:10.3109/17518423.2011.568467. [PubMed: 21732803].

12. Stevenson RD, Conaway $M$, Chumlea WC, Rosenbaum P, Fung $\mathrm{EB}$, Henderson RC, et al. Growth and health in children with moderate-to-severe cerebral palsy. Pediatrics. 2006;118(3):1010-8. doi: 10.1542/peds.2006-0298. [PubMed: 16950992].

13. Kuperminc MN, Stevenson RD. Growth and nutrition disorders in children with cerebral palsy. Dev Disabil Res Rev. 2008;14(2):137-46. doi: 10.1002/ddrr.14. [PubMed:18646022].

14. Stevenson RD. Use of segmental measures to estimate stature in children with cerebral palsy. Arch Pediatr Adolesc Med. 1995;149(6):658-62. doi: 10.1001/archpedi.1995.02170190068012. [PubMed: 7767422].

15. Virginia K. Nelson textbook of pediatrics. 18th ed. Philadelphia: Saunders Elsevier; 2008. Assessment of Growth.

16. Brooks J, Day S, Shavelle R, Strauss D. Low weight, morbidity, and mortality in children with cerebral palsy: new clinical growth charts. Pediatrics. 2011;128(2):e299-307. doi: 10.1542/peds.2010-2801. [PubMed: 21768315].

17. Willett W. Overview of Nutritional Epidemiology. 1998 :3-17. doi: 10.1093/acprof:oso/9780195122978.003.01.

18. Feskanich D, Sielaff BH, Chong K, Buzzard IM. Computerized collection and analysis of dietary intake information. Comput Methods Programs Biomed. 1989;30(1):47-57. doi:10.1016/0169-2607(89)90122-3. [PubMed: 2582746].

19. Dahlseng MO, Finbraten AK, Juliusson PB, Skranes J, Andersen G, Vik T. Feeding problems, growth and nutritional status in children with cerebral palsy. Acta Paediatr. 2012;101(1):92-8. doi: 10.1111/j.16512227.2011.02412.x. [PubMed: 21767308]. 
20. Tuzun EH, Guven DK, Eker L, Elbasan B, Bulbul SF. Nutritional status of children with cerebral palsy in Turkey. Disabil Rehabil. 2013;35(5):4137. doi: 10.3109/09638288.2012.694965. [PubMed: 22725837].

21. Rogozinski BM, Davids JR, Davis RB, Christopher LM, Anderson JP, Jameson GG, et al. Prevalence of obesity in ambulatory children with cerebral palsy. J Bone Joint Surg Am. 2007;89(11):2421-6. doi: 10.2106/JBJS.F.01080. [PubMed: 17974884].

22. Park ES, Chang WH, Park JH, Yoo JK, Kim SM, Rha DW. Childhood obesity in ambulatory children and adolescents with spastic cerebral palsy in Korea. Neuropediatrics. 2011;42(2):60-6. doi: 10.1055/s-00311279724. [PubMed: 21611937].

23. Reilly S, Skuse D. Characteristics and management of feeding problems of young children with cerebral palsy. Dev Med Child Neurol. 1992;34(5):379-88. doi: 10.1111/j.1469-8749.1992.tb11449.x. [PubMed: 1592191].

24. Stallings VA, Zemel BS, Davies JC, Cronk CE, Charney EB. Energy expenditure of children and adolescents with severe disabilities: a cerebral palsy model. Am J Clin Nutr. 1996;64(4):627-34. [PubMed: 8839510].

25. Samson-Fang L, Fung E, Stallings VA, Conaway M, Worley G, Rosenbaum $\mathrm{P}$, et al. Relationship of nutritional status to health and societal participation in children with cerebral palsy. J Pediatr. 2002;141(5):637-43. doi: 10.1067/mpd.2002.129888. [PubMed: 12410191].

26. Liptak GS, O’Donnell M, Conaway M, Chumlea WC, Wolrey G, Henderson RC, et al. Health status of children with moderate to severe cerebral palsy. Dev Med Child Neurol. 2001;43(6):364-70. doi: 10.1111/j.14698749.2001.tb00223.x. [PubMed: 11409824].

27. Sullivan PB, Juszczak E, Lambert BR, Rose M, Ford-Adams ME, Johnson A. Impact of feeding problems on nutritional intake and growth: Oxford Feeding Study II. Dev Med Child Neurol. 2002;44(7):461-7. doi: 10.1111/j.1469-8749.2002.tb00307.x. [PubMed: 12162383].

28. Stallings VA, Charney EB, Davies JC, Cronk CE. Nutritional sta- tus and growth of children with diplegic or hemiplegic cerebral palsy. Dev Med Child Neurol. 1993;35(11):997-1006. doi: 10.1111/j.14698749.1993.tb11582.x. [PubMed: 8224567].

29. Stallings VA, Charney EB, Davies JC, Cronk CE. Nutrition-related growth failure of children with quadriplegic cerebral palsy. Dev Med Child Neurol. 1993;35(2):126-38. doi: 10.1111/j.1469-8749.1993.tb11614.x. [PubMed: 8444326].

30. Stallings VA, Cronk CE, Zemel BS, Charney EB. Body composition in children with spastic quadriplegic cerebral palsy.J Pediatr. 1995;126(5 Pt 1):833-9. doi: 10.1016/S0022-3476(95)70424-8. [PubMed: 7752019].

31. Hogan SE. Energy requirements of children with cerebral palsy. Can J Diet Pract Res. 2004;65(3):124-30. doi:10.3148/65.3.2004.124. [PubMed: 15363117].

32. Krick J, Murphy PE, Markham JF, Shapiro BK. A proposed formula for calculating energy needs of children with cerebral palsy. Dev Med Child Neurol. 1992;34(6):481-7. doi: 10.1111/j.1469-8749.1992.tb11468.x. [PubMed: 1612207].

33. Rose J, Medeiros JM, Parker R. Energy cost index as an estimate of energy expenditure of cerebral-palsied children during assisted ambulation. Dev Med Child Neurol. 1985;27(4):485-90. doi: 10.1111/j.14698749.1985.tb04572.x. [PubMed: 4029518].

34. Rose J, Gamble JG, Burgos A, Medeiros J, Haskell WL. Energy expenditure index of walking for normal children and for children with cerebral palsy. Dev Med Child Neurol. 1990;32(4):333-40. doi: 10.1111/j.14698749.1990.tb16945.x. [PubMed: 2332124].

35. Grammatikopoulou MG, Daskalou E, Tsigga M. Diet, feeding practices, and anthropometry of children and adolescents with cerebral palsy and their siblings. Nutrition. 2009;25(6):620-6. doi: 10.1016/j.nut.2008.11.025. [PubMed: 19216055].

36. Caram ALA, Morcillo AM, da Costa Pinto EAL. Estado nutricional de crianças com paralisia cerebral. Rev Nutr. 2010;23(2):211-9. doi $10.1590 /$ s1415-52732010000200004 